\title{
Desertification in the Sahel: a reinterpretation of a reinterpretation
}

\author{
STEPHEN D. PRINCE*, KONRAD J. WESSELS*, COMPTON J. TUCKER† and \\ SHARON E. NICHOLSON \\ *Geography Department, Rm 2181 LeFrak Hall, University of Maryland, College Park, MD 20742-8225, USA, †Biospheric Sciences \\ Branch Code 614.4, NASA/Goddard Space Flight Center, Greenbelt, MD 20771, USA, $\ddagger$ Department of Meteorology, Florida State \\ University, Tallahassee, FL 32306, USA
}

\begin{abstract}
In semiarid regions the ratio of annual net primary production to precipitation, rain-use efficiency (RUE), has been used as an index of desertification. In a recent publication (Hein \& de Ridder, 2006) it was proposed that an incorrect understanding of the relationship between RUE and rainfall has led to a misinterpretation of the satellite record of desertification in the African Sahel. Here, we examine this suggestion and show that, contrary to Hein and de Ridder's statement, satellite studies of Sahelian RUE have reported increases, decreases, and constant values since 1981. Furthermore, we find that data do not support their proposal that RUE increases with rainfall, even in nondegraded areas. Hence we reject their corollary, that constant RUE is prima facie evidence of desertification. The fundamental difficulty with the use of RUE for detection of desertification remains, that is the difficulty of estimation of the RUE for nondegraded land at a regional scale.
\end{abstract}

Keywords: Africa, AVHRR, degradation, desertification, net primary production, rainfall, rain-use efficiency, Sahel, satellite, semiarid

Received 21 August 2006; revised version received 22 February 2007 and accepted 16 November 2006

\section{Introduction}

Several authors have concluded that the ratio of net primary production (NPP) of vegetation to rainfall [rain-use efficiency (RUE)] in the semiarid African Sahel does not indicate widespread desertification during the 1980s and 1990s (Nicholson et al., 1998; Prince et al., 1998) (the term desertification is used interchangeably with degradation following UNCCD, 1994). This view is challenged by Hein \& de Ridder (2006) on the basis of the following claims. (1) Ecological theory indicates that RUE decreases as rainfall declines relative to the longterm mean for a site. (2) RUE calculated using satellite measurements of NPP have not found the increase in RUE that would be expected because of the general rise in rainfall in the Sahel over the past 20 years. (3) The invariant RUE should be reinterpreted, not as evidence for lack of degradation, but rather that there has been widespread degradation in the Sahel. The first proposition is incorrect as it is based on the use of total rainfall

Correspondence: Stephen D. Prince, tel. +1 301405 4062, fax +1 301314 9299, e-mail: sprince@geog.umd.edu rather than available soil moisture (sometimes called effective rainfall) and, furthermore, the behavior of RUE as rainfall declines is subject to large errors owing to the uncertainty of its value close to zero rainfall. The second proposition is incorrect as satellite studies of the Sahel of the past 20 years have found areas where RUE has increased, as well as areas with constant and decreasing RUE. The rejection of propositions 1 and 2 leads to the rejection of the third, and so we find there is no basis to reconsider the conclusion that RUE indicates no widespread desertification in the Sahel since the beginning of the satellite record in 1981.

Relationship between satellite observations of RUE and rainfall

In satellite studies of NPP and rainfall in semiarid regions it has often been noted that the RUE declines above a high threshold rainfall (e.g. $800 \mathrm{~mm}$ in the tropics, lower in winter rainfall regions), as indicated by the decline in the slope of a regression fitted to the data shown in Fig. 1. The relationship between rainfall and available moisture changes as the proportion lost to 


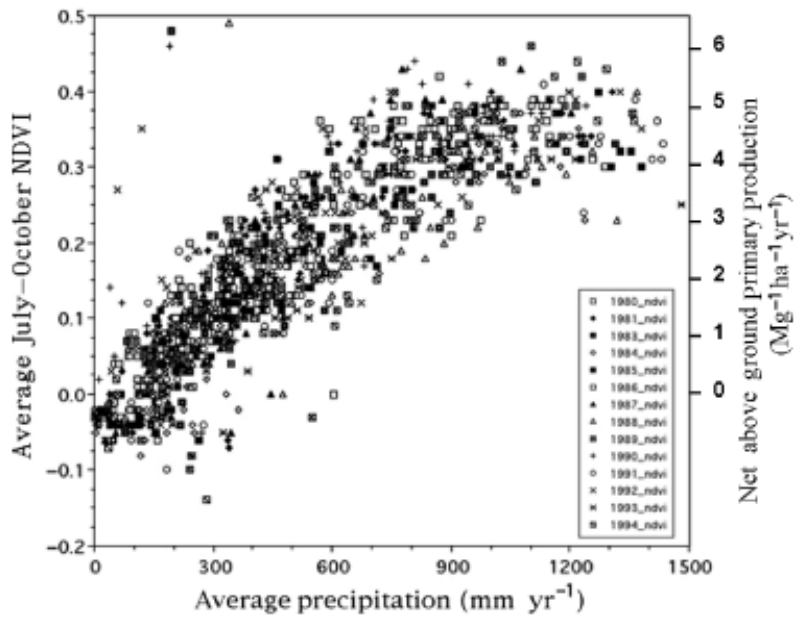

Fig. 1 Average normalized difference vegetation index (NDVI) for growing season and rainfall for the Sahel from 1980 to 1994 at rain gauge stations. The same Sahel regional boundaries were used as in Anyamba \& Tucker (2005). Net primary production (NPP) was calculated using the regression equation NPP $\left(\mathrm{Mg} \mathrm{ha}^{-1} \mathrm{yr}^{-1}\right)=[(0.114 \times$ average $\mathrm{NDVI} \times 123 d)-0.086]$ from Prince (1991). Note that there is no evidence at low rainfall for a nonlinear relationship of NPP and rainfall. The expected saturation at high rainfall occurs above approximately $800 \mathrm{~mm}$. These data also show that, at zero rainfall, NDVI is often negative, and that zero NPP occurs when rainfall is still above zero.

runoff progressively increases. Moreover, satisfaction of the water requirement probably leads to limitation by other factors such as nutrition, as expressed by the law of limiting factors (e.g. Nicholson et al., 1998; Prince et al., 1998; Paruelo et al., 1999). However, high rainfall is much more localized than low rainfall and so the high totals at an individual station may not be representative of the conditions in the large area corresponding to a coarse resolution satellite measurement of NPP.

Neither NPP nor available soil moisture can be measured accurately at very low rainfall, yet slight errors in these lead to dramatic changes in RUE. In studies that use satellite data, available soil moisture is often assumed to be the intercept of NPP on the rainfall axis obtained by extrapolation of a regression line calculated between rainfall and NPP estimated by satellite measurements of the seasonal sum of the normalized difference vegetation index (NDVI) at higher rainfall (e.g. Huxman et al., 2004) or it is assumed to be the same as rainfall. However, the relationship between available soil moisture and total rainfall depends on many local environmental factors, such as within-season distribution of rainfall (e.g. Martiny et al., 2006), rainfall rates, infiltration rates, and soil water retention, and also on plant factors such as increases in the ratio of evaporation to transpiration, reduced plant water-use efficiency at higher temperatures, thresholds in soil moisture required for growth initiation, and nonlinear responses of photosynthesis and leaf tissue mortality to water stress - variables that cannot be measured over large areas. Except for transient high and low rainfall events (Goward \& Prince, 1995; Prince et al., 1998; Huxman et al., 2004), we are not aware of any ecological reasons for a fall in RUE at low rainfall if, (1) NPP is measured accurately, (2) available soil moisture is used in the calculation and, (3) potential physiological differences are considered.

The fall in RUE as rainfall declines presented in Hein and de Ridder's Fig. 1 may not represent any fundamental ecological process, as it would occur simply because rainfall rather than available soil moisture was used in their calculation. A similar effect arises if untransformed NDVI is used as a surrogate for NPP, as bare ground generally has NDVI $>0$. The differences between rainfall and available soil moisture and between zero NDVI and NDVI at zero NPP lead to meaningless tendencies of RUE to zero or infinity. The effect depends on how accurate are the measures NPP and available soil moisture. NPP with total rainfall causes RUE to tend to zero at low rainfall, while an overestimate of NPP (e.g. using untransformed NDVI) results in RUE tending to infinity. Thus, the declines in RUE with rainfall that are the basis of Hein and de Ridder's re-interpretation could occur for a mathematical reason without any interaction between rainfall and NPP. For their 'satellite' RUE, Hein and de Ridder do not say which offsets, if any, were applied. Many studies have shown that RUE calculated with the appropriate offsets is constant at low rainfall (Prince et al., 1998).

Hein \& de Ridder (2006) propose that RUE should follow a quadratic relationship with rainfall and they present field data from six sites in support of this. Unfortunately, each site has only between seven and 17 points and, in several, the RUE for high and low rainfall depends on single observations, so the fitted curves inevitably have very wide confidence limits that prevent useful comparisons of linear and quadratic regressions. Inclusion of years with high rainfall, significantly above the range considered here, is a justifiable reason for the use of a quadratic, but this forces nonlinearity on the low rainfall end which is not supported by the data. Moreover, because RUE is a ratio of NPP to rainfall, it is not independent of rainfall and so regression of RUE on rainfall violates the requirement of independence. This dependency does not occur if NPP is regressed on rainfall rather than RUE (Fig. 1) (Tucker et al., 1991a; Prince et al., 1998). When the six data sets used by Hein and de Ridder were reanalyzed by regressing NPP on rainfall, no convincing evidence of an improvement of a quadratic over linear regression 
was found (Table 1) beyond the improved fit provided by the extra regression term. Thus, there is no reason to conclude that there is any reduction in RUE at low rainfall.

\section{Effects of interannual variation in rainfall}

The ecological arguments advanced in support of Hein and de Ridder's proposed relationship between NPP and rainfall are entirely reasonable as far as they go, but

Table 1 Regression analyses of NPP on rainfall for the six sites used by Hein \& de Ridder (2006)

\begin{tabular}{|c|c|c|c|}
\hline \multirow{2}{*}{$\begin{array}{l}\text { Site (number of } \\
\text { observations) }\end{array}$} & \multirow[b]{2}{*}{ Statistic } & \multicolumn{2}{|c|}{ Regression model } \\
\hline & & Linear & Quadratic \\
\hline \multirow{4}{*}{ South Africa (17) } & $R^{2}$ & 0.7201 & 0.7208 \\
\hline & Constant & ns & ns \\
\hline & $x$ & * & ns \\
\hline & $x^{2}$ & & ns \\
\hline \multirow[t]{4}{*}{ Negev (11) } & $R^{2}$ & 0.7260 & 0.7474 \\
\hline & Constant & ns & ns \\
\hline & $x$ & $*$ & ns \\
\hline & $x^{2}$ & & ns \\
\hline \multirow[t]{4}{*}{ Kuwait (10) } & $R^{2}$ & 0.8900 & 0.8956 \\
\hline & Constant & ns & ns \\
\hline & $x$ & * & ns \\
\hline & $x^{2}$ & & ns \\
\hline \multirow[t]{4}{*}{ Chubut (10) } & $R^{2}$ & 0.0759 & 0.2938 \\
\hline & Constant & ns & ns \\
\hline & $x$ & ns & ns \\
\hline & $x^{2}$ & & ns \\
\hline \multirow[t]{4}{*}{ Ferlo (10) } & $R^{2}$ & 0.6906 & 0.8046 \\
\hline & Constant & ns & ns \\
\hline & $x$ & $* *$ & * \\
\hline & $x^{2}$ & & ns \\
\hline \multirow[t]{4}{*}{ Gadabedji (7) } & $R^{2}$ & 0.5946 & 0.8000 \\
\hline & Constant & ns & ns \\
\hline & $x$ & * & ns \\
\hline & $x^{2}$ & & ns \\
\hline
\end{tabular}

RUE and rainfall were estimated from their Fig. 1 and used to calculate NPP. The regression $R^{2}$, the significance of the constant, linear $(x)$, and quadratic $\left(x^{2}\right)$ rainfall terms are shown (ns, not significant, ${ }^{*} P<0.05,{ }^{* *} P<0.01$ ). The highest rainfall points were omitted for the Ferlo, South Africa, and Chubut sites because the aim was to compare the regressions at low to median rainfall and these points had approximately twice the mean rainfall. There was no convincing evidence that a quadratic is any better than a linear model. The similarity was increased when the regressions were forced through the origin. Note that the data Hein and de Ridder used for the Ferlo site are said by their source Miehe (nee Klug) (2006) to be incorrect, and the data for Gadabedji were not found in the source cited by Hein and de Ridder Wylie et al. (1992). RUE, rain-use efficiency; NPP, net primary production. they omit other effects such as interannual and seasonal variability in rainfall that can completely alter the relationship of NPP and rainfall between successive years. Both temporal and spatial variations in rainfall are normal in semiarid areas including the Sahel; coefficients of variation between $30 \%$ and $40 \%$ are common (Nicholson, 1996, 2001; Le Barbe \& Lebel, 1997), and up to $90 \%$ has been reported. In fact a high coefficient of variability is a better way than a rainfall range to define the Sahel (Tucker et al., 1991b). The effect of such variability is that there is often an increase of RUE in a dry year following a wet one, and a decrease in RUE in a wet year following a drier one (Prince et al., 1998; O'Connor et al., 2001; Wessels et al., 2007). One explanation of this pattern is that there is a lag in the response of the vegetation to changes in rainfall, so that NPP in 1 year is partly affected by rainfall in previous years (Goward \& Prince, 1995; Oesterheld et al., 2001; Huxman et al., 2004; Wiegand et al., 2004). RUE averaged over very large regions such as the entire Sahel (Nicholson et al., 1998) and over multiple years (Prince et al., 1998) generally exhibits less variability, but some studies in regions where the coefficient of variation of annual rainfall is especially high have not found a stabilizing effect of multiyear averages (Wessels et al., 2007).

\section{Changes in RUE in the Sahel}

Hein and de Ridder are incorrect in their statement that satellite data indicate constant values of RUE ('remote sensing did not detect any significant change in the rain-use efficiency in the Sahel in the period 1980$2000^{\prime}$ ), but do not give the source of the constant satellite RUE in their Table 1, and so it cannot be evaluated. Prince et al. (1998) state: 'the ... regression (RUE on year) ... showed significant increases in RUE through the 9 year sequence $(P<0.005)^{\prime}$ (Fig. 2$)$, furthermore, Herrmann et al. (2005) show that this trend has continued to present, that is over 22 years. In a study of a longer period in the Sahel, using complete spatial coverage (Fig. 3), we found areas with declining, constant, and increasing RUE in agreement with other studies of the region (e.g. Herrmann et al., 2005).

\section{Discussion}

The concept behind RUE is that, in dry regions, annual NPP is primarily determined by annual rainfall because of a correlation between rainfall, available soil moisture, and vegetation production (Farrar et al., 1994; Prince et al., 1998). Only at rainfall amounts above normal do other resources such as nutrients and light affect NPP. Rainfall is, in effect, used as a surrogate for potential 
NPP that can be compared with the actual, measured NPP. In degraded conditions it is further supposed that RUE falls (Diouf \& Lambin, 2001) because of changes in the correlation caused, for example, by lower infiltration, increased evaporation, reduced water holding

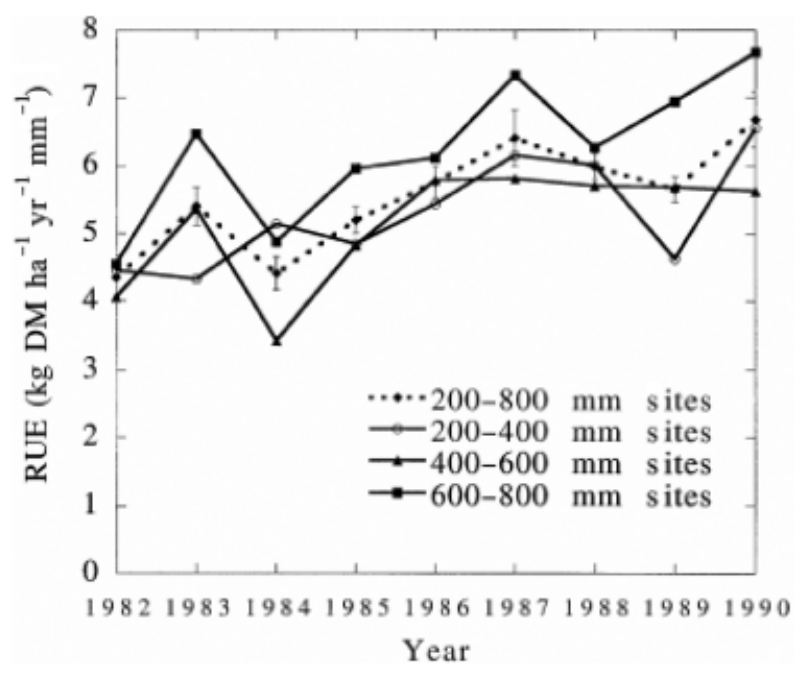

Fig. 2 Annual rain-use efficiencies (RUE) for 214 sites in all Sahelian countries grouped by long-term (1961-1990) rainfall means. Regressions fitted to the individual data sets and to the ensemble all showed significant increases in RUE through the 9-year sequence $(P<0.05)$. Figure reproduced from Prince $e t$ al. (1998). capacity, loss of organic matter, erosion, or depletion of the seed bank (Prince et al., 1998). The onset of degradation can be expected to take longer than shortterm fluctuations in rainfall and so studies need to extend over appropriately long periods (Prince, 2002).

In order to detect degradation using RUE there has to be a reference value for the non-, or less-degraded condition. Hein and de Ridder's criterion (lack of increase in RUE with rainfall) is based on an incomplete model of rain and RUE. No methods are proposed by which a reference RUE might be established, and so there is no foundation on which to state that the RUE for the Sahel indicates extensive degradation. It is possible to infer the nondegraded RUE from sites that share all the same conditions such as soils and vegetation but are known not to be degraded (Diouf \& Lambin, 2001; Prince, 2004). A fundamental difficulty in this approach, however, is to identify such nondegraded sites at the appropriate time and space scales (Wessels et al., 2007). Prince (2004) describes a technique, called local NPP scaling, in which the maximum NPP found in strata defined by climate, soils, and vegetation type is used to estimate the nondegraded NPP in that stratum. In the absence of reference sites, however, RUE can only be compared with itself noting, for example, any interannual trends.

A method that identifies interannual trends using deviations from the regression of NPP on rainfall for

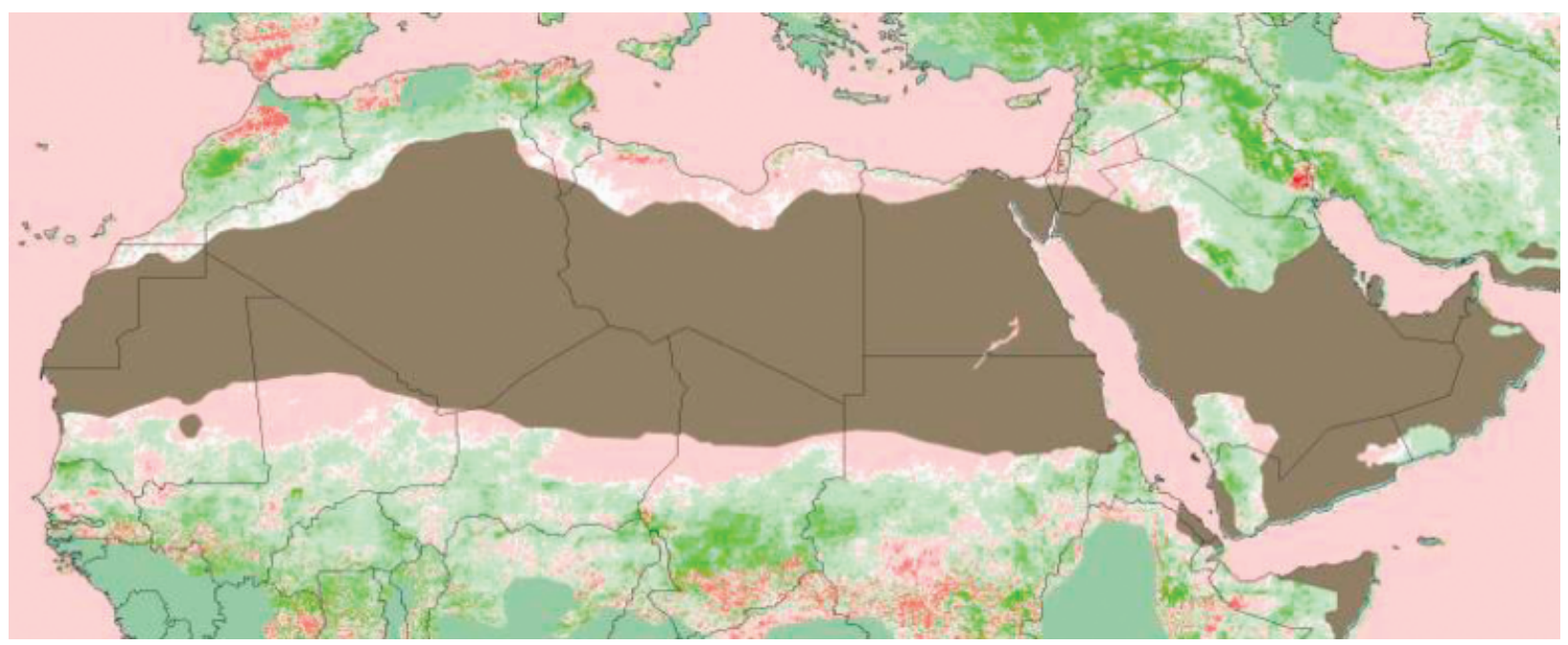

Fig. 3 Interannual residual trends in deviations of normalized difference vegetation index (NDVI) from the expected values indicated by annual rainfall (Wessels et al., 2007). For each pixel, annual NDVI was regressed on annual rainfall for all years [i.e. the mean rain-use efficiency (RUE) for the pixel] and the deviation of the NDVI for each year from the regression was calculated. These deviations were regressed on year and the slope for each pixel is mapped. Hyperarid and humid zones are masked in tan and light green, respectively. Pink, white, and light green indicates areas where the regression of NDVI deviations on year were not significantly different from zero $(P<0.05)$. Red indicates pixels that had a significant decline (negative deviations) and dark green pixels had a significant increase (positive deviations). Thus, during the 19-year period 1981-1999, RUE was constant in all except red and dark green areas. Spatially smoothed Global Precipitation Climatology Project data and maximum-value composited 15-day NDVI from Tucker et al. (2005) were used. 
the nondegraded condition is described by Evans \& Geerken (2004) and Wessels et al. (2007) (Fig. 3). Consistent negative trends in the deviations through time may indicate degradation, and positive trends recovery. The relationship of NPP and rainfall for nondegraded sites is estimated using a best fit to the entire time series thus the difficulties in estimation of NPP at low rainfall are avoided. While the results can be misleading for sites that were degraded before the time series started, the procedure does identify areas for more detailed examination. In an application of this method to the Sahel (Fig. 3), the greater part of the region had no significant trend and was, therefore, unlikely to be undergoing desertification during the period of observations. Small areas, for instance in central Senegal, southern Chad, and central Sudan, had negative trends that may indicate active degradation while larger areas, such as central Chad and eastern Sudan, had evidence of recovery. By far, the greater part of the Sahel had no significant trends, a finding that does not support Hein and de Ridder's reinterpretation of the satellite record. Retzer (2006) also cast doubt on the reinterpretation, in their case by showing that nonequilibrium vegetation dynamics could account for Hein and de Ridder's results.

Biogeochemical modeling (e.g. Penning de Vries \& Djitèye, 1982; Ellis \& Coughenour, 1998; Parton et al., 2004; Tracol et al., 2006) is needed to account for correlations of rainfall and NPP. Key factors to consider include precipitation (seasonal distribution, phenology of vegetation, rain rate, antecedent rainfall, runoff, infiltration, crusting, water content-available soil moisture relationship), net production (annual and perennial, species composition, above- and belowground, lags in seed, and bud banks), and other factors (mineral nutrient limitation, erosion, trampling leading either to compaction and increased runoff or breakage of biological crust and shallow infiltration with subsequent loss by evaporation, salinity) (O'Connor et al., 2001). Were appropriate models to be parameterized for areas from field sites of a few hectares to multiple satellite pixels $\left(10-100 \mathrm{~km}^{2}\right)$, and for within-season time periods to 20 years, it may be possible to advance beyond correlation to account for the patterns found in remotely sensed measurements (Niemeijer \& Mazzucato, 2002; Retzer, 2006).

New types of remotely sensed data, for example rainfall (Funk et al., 2003; Dinku et al., 2007), soil moisture (phased array type L-band synthetic aperture radar), vegetation cover (advanced land imager), and the sensor suite planned for NPP (NPOESS Preparatory Project), that have recently become available or are planned for the near future, can be expected to allow more sophisticated rainfall-NPP models to be used at a regional scale and with higher spatial resolution. These measurements will still need to be combined, however, with soil and vegetation studies on the surface (Niemeijer \& Mazzucato, 2002).

Nicholson et al. (1998) and Prince et al. (1998) base their conclusions, that there is no evidence for dramatic degradation in the Sahel, on the lack of a downward trend in RUE from satellite observations over the 12 and 9 years that were analyzed, respectively. The results in Fig. 3 and Herrmann et al. (2005) provide further evidence. As we found no widespread decline in RUE, nor downward trends in deviations from longerterm RUE, we do not find any evidence in support of Hein and de Ridder's proposed relationship between low rainfall and RUE, and therefore no basis on which to reinterpret the conclusions of studies of RUE in the Sahel.

\section{Conclusions}

The uncertainties that arise from the inclusion of a constant in calculation of RUE, the use of an inappropriate-dependent variable (RUE), the lack of information on the NPP at very low rainfall, and the probable overfitting of the regressions as a result of the use of a second-order polynomial regression, seem the most likely explanations of Hein and de Ridder's results. These, together with a mistaken reading of published time series of RUE for the Sahel, seem to have led to their misinterpretation of RUE evidence.

\section{References}

Anyamba A, Tucker CJ (2005) Analysis of Sahelian vegetation dynamics using NOAA-AVHRR NDVI data from 1981-2003. Journal of Arid Environments, 63, 596-614.

Dinku T, Ceccato P, Grover-Kopec E, Lemma M, Connor SJ, Ropelewski CF (2007) Validation of satellite rainfall products over East Africa's complex topography. International Journal of Remote Sensing, 68, 271-297.

Diouf A, Lambin EF (2001) Monitoring land-cover changes in semi-arid regions: remote sensing data and field observations in the Ferlo, Senegal. Journal of Arid Environments, 48, 129-148.

Ellis JE, Coughenour MB (1998) The SAVANNA integrated modelling system: an integrated remote sensing, GIS and spatial simulation modelling approach. In: Drylands: Sustainable Use of Range Lands into the Twenty-First Century (eds Squires VR, Sidahmed AE), pp. 97-106. IFAD Series, Technical Report, Rome.

Evans J, Geerken R (2004) Discrimination between climate and human-induced dryland degradation. Journal of Arid Environments, 57, 535-554.

Farrar TJ, Nicholson SE, Lare AR (1994) The influence of soil type on the relationships between NDVI, rainfall and soil moisture 
in semi-arid Botswana. Part II. Response to soil moisture. Remote Sensing of Environment, 50, 121-133.

Funk CJ, Michaelsen J, Verdin J, Artan G, Husak G, Senay G, Gadain H, Magadazire T (2003) The collaborative historical African rainfall model: description and evaluation. International Journal of Climatology, 23, 47-56.

Goward SN, Prince SD (1995) Transient effects of climate on vegetation dynamics: satellite observations. Journal of Biogeography, 22, 549-563.

Hein L, de Ridder N (2006) Desertification in the Sahel: a reinterpretation. Global Change Biology, 12, 751-758.

Herrmann SM, Anyamba A, Tucker CJ (2005) Recent trends in vegetation dynamics in the African Sahel and their relationship to climate. Global Environmental Change, 15, 394-404.

Huxman TE, Smith MD, Fay PA et al. (2004) Convergence across biomes to a common rain-use efficiency. Nature, $\mathbf{4 2 9}$, 651-654.

Le Barbe L, Lebel T (1997) Rainfall climatology of the HAPEXSahel region during the years 1950-1990. Journal of Hydrology, 188-189, 43-73.

Martiny N, Camberlin P, Richard Y, Phipippon N (2006) Compared regimes of NDVI and rainfall in semi-arid regions of Africa. International Journal of Remote Sensing, 27, 1366-5901, doi: 10.1080/01431160612331392554.

Miehe (nee Klug) S (2006) Comment on: Hein, L. 2006: The impacts of grazing and rainfall variability on the dynamics of a Sahelian rangeland. J. Arid Environ. 64(3):488-504. Journal of Arid Environments, 67, 174-176.

Nicholson SE (1996) Environmental change within the historical period. In: The Physical Geography of Africa (eds Goudie AS, Adams WM, Orme A), pp. 60-75. Oxford University Press, Oxford.

Nicholson SE (2001) Climatic and environmental change in Africa during the last two centuries. Climatic Change, 17, 123-144.

Nicholson SE, Tucker CJ, Ba MB (1998) Desertification, drought, and surface vegetation: an example from the West African Sahel. Bulletin of the American Meteorological Society, 79, 1-15.

Niemeijer D, Mazzucato V (2002) Soil degradation in the West African Sahel. How serious is it? Environment, 44, 20-31.

O'Connor TG, Haines LM, Snyman HA (2001) Influence of precipitation and species composition on phytomass of a semi-arid African grassland. Journal of Ecology, 89, 850-860.

Oesterheld M, Loreti J, Semmartin M, Sala OE (2001) Interannual variation in primary production of a semi-arid grassland related to previous-year production. Journal of Vegetation Science, 12, 137-142.

Parton W, Tappan G, Ojima D, Tschakert P (2004) Ecological impact of historical and future land-use patterns in Senegal. Journal of Arid Environments, 59, 605-623.

Paruelo JM, Lauenroth WK, Burke IC, Sala OE (1999) Grassland precipitation-use efficiency varies across a resource gradient. Ecosystems, 2, 64-68
Penning de Vries FWT, Djitèye MA (1982) La Productivité des Pasturages Sahélien: Une étude des sols des végétations et de l'exploitation de cette ressource naturelle. Pudoc, Centre for Agricultural Publishing and Documentation, Wageningen, the Netherlands.

Prince SD (1991) Satellite remote sensing of primary production: comparison of results for Sahelian grasslands 1981-1988. International Journal of Remote Sensing, 12, 1301-1311.

Prince SD (2002) Spatial and temporal scales of measurement of desertification. In: Global Desertification: Do Humans Create Deserts? (eds Stafford-Smith M, Reynolds JF), pp. 23-40. Dahlem University Press, Berlin.

Prince SD (2004) Mapping desertification in Southern Africa. In: Land Change Science: Observing, Monitoring, and Understanding Trajectories of Change on the Earth's Surface (eds Gutman G, Janetos A, Justice CO, Moran EF, Mustard JF, Rindfuss RR, Skole D, Turner II BL), pp. 163-184. Kluwer, Dordrecht, the Netherlands.

Prince SD, Brown de Colstoun E, Kravitz L (1998) Evidence from rain use efficiencies does not support extensive Sahelian desertification. Global Change Biology, 4, 359-374.

Retzer V (2006) Impacts of grazing and rainfall variability on the dynamics of a Sahelian rangeland revisited - new insights from old data. Journal of Arid Environments, 67, 157-164.

Tracol Y, Mougin E, Hiernaux P, Jarlan L (2006) Testing a sahelian grassland functioning model against herbage mass measurements. Ecological Modelling, 193, 437-446.

Tucker CJ, Dregne HE, Newcomb WW (1991a) Expansion and contraction of the Sahara desert from 1980 to 1990. Science, 253, 299-301.

Tucker CJ, Newcomb WW, Los SO, Prince SD (1991b) Mean and inter-annual variation of growing-season normalized difference vegetation index for the Sahel 1981-1989. International Journal of Remote Sensing, 12, 1133-1135.

Tucker CJ, Pinzon JE, Brown ME, Slayback DA, Pak EW, Mahoney R, Vermote EF, El Saleous N (2005) An extended AVHRR $8 \mathrm{~km}$ NDVI data set compatible with MODIS and SPOT VEGETATION NDVI data. International Journal of Remote Sensing, 26, 4485-4498.

UNCCD (1994) Elaboration of an international convention to combat desertification in countries experiencing serious drought and/or desertification, particularly in Africa. United Nations General Assembly, 93rd Plenary Meeting, New York.

Wessels KJ, Prince SD, Malherbe J, Small J, Frost PE, VanZyl D (2007) Can human-induced land degradation be distinguished from the effects of rainfall variability? A case study in South Africa. Journal of Arid Environments, 68, 271-297.

Wiegand T, Snyman HA, Kellner K, Paruelo JM (2004) Do grasslands have a memory: modeling phytomass production of a semiarid South African grassland. Ecosystems, 7, 243-258.

Wylie BK, Pieper RD, Morris Southwood G (1992) Estimating herbage standing crop from rainfall data in Niger. Journal of Arid Environments, 45, 277-284. 